others the temperature has been raised to 33 C. $(91.4$ F.) and the humidity to over 89 per cent.; that is, one group of animals has been kept under favorable conditions, the other group has been given the air of a hot and humid New York summer day. Under the latter conditions the animals' bodily temperature rises, on an average, 0.5 degree $C$. or nearly 1 degree $F$. At the end of the period of six hours the cat is taken from the chamber and killed, and certain of the muscles are removed, attached to levers and stimulated by regularly applied electric shocks. The contractions are recorded graphically and the total duration of the working period and the total amount of work done before the muscle becomes exhausted are determined. It is found that the three muscles studied, the diaphragm, the extensor longus digitorum and the sartorius, are capable of performing a total amount of work which is less by 14,18 and 26 per cent., respectively, in the animals exposed to the high heat and humidity than in those that have been subjected to the more comfortable atmospheric conditions. It would thus appear that the inefficiency of an individual under such unfavorable air conditions is not a matter of the nervous system only as might be inferred, but a matter of the muscles as well. Furthermore, we find that along with the muscular effect, the sugar of the blood is diminished from $0.069 \mathrm{gm}$. per cent. to 0.060 , a diminution of 13 per cent. The meaning of this is not yet clear, but it helps to indicate that the effect of unfavorable air conditions on the individual is more far-reaching than has heretofore been demonstrated.

It is by studies of this general nature that the laboratory is yet capable, I believe, of throwing much light on the general problem of the air in its physiologic relations. We must consent to a detailed analysis of the problem. To reiterate over and over again that air that has once been breathed is "bad" air and that "bad" air is "bad" air, without defining in what its badness consists, is a sin against not only scientific reasoning, but also common sense-and yet $I$ have seen that $\sin$ committed. To urge, moreover, the great virtues of "fresh" air without making an effort to determine in what the virtues of "freshness" consist, is suggestive of a mind that has not yet reached the sophomoric stage of its development-and yet such minds exist. The opponents of the laboratory doctrine of fresh air sometimes add to the gaiety of nations by speaking of such air in England as "tinned" air and in America as "canned" air. They forget that a canned thing is a dead thing, something without the power of moving of itself or of stimulating others. But the fresh air that we advocate with its coolness, its comparative dryness, and its constant motion is anything but lifeless. Its qualities are those which conduce most to the efficiency of the individual. Constant monotony in air conditions should be avoided like monotony in other conditions of life. It is not my function here to advise regarding ventilating methods, but it is obvious, I think, that no ventilating method can be expected to be effective unless it is based on the facts regarding human well-being which the laboratory is able to supply.

The Catholicity of Medicine.-The human being is a part of the whole of nature and cannot be understood without it. What is wanted is a satisfactory general view of the process of the universe. Possessing this, we shall find the key in our hands which will open the most secret recesses of the art of medicine.-Gomperz.

\section{HOSPITAL VENTILATION FROM THE VENTILATING ENGINEER'S POINT OF VIEW*}

\section{A. K. OHMES \\ NEW YORK}

Inscribed under the statue of Hygeia gracing the entrance of a foreign hospital are words with the following meaning:

One names as the greatest earthly fortune, Health. I contradict; a greater one is Convalescence.

It is difficult to express more forcefully in a few words the noble purpose of the hospital, and the responsibilities of those who are most intimately connected with its management. It also implies to architects and engineers that there can be no building worthy of greater effort than a hospital. One of the important items in the construction and operation of a hospital is that of providing "ventilation" for its various rooms. Ventilation means to supply pure fresh air (from some source, no matter from where) and the removal of vitiated air, both in as simple, positive and inoffensive ways as possible.

There is, of course, no medical man who does not value "pure fresh air," who is not deeply interested in securing it, whether in the so-called "natural" way (by means of open windows) or in the so-called "artificial" way (by means of a ventilating system) and who would not treat this subject with an open mind, ready to hear arguments for and against either method. Similarly every architect and engineer should treat the subject with an open mind, ever realizing that by far the greater portion of humanity lives and remains happy and healthy in its homes, where only the socalled natural or window ventilation exists. The special object of this paper, however, will be to bring forth arguments of how far artificial ventilation might prove helpful in solving the problem of the positive, simple and effective supply of fresh air and the removal of vitiated air, irrespective of wind and weather, under every-varying conditions, in many different departments of a hospital.

Let $u$ s be frank and acknowledge that a number of persons in any enclosed space are rarely in perfect agreement as to the quality and freshness of the confined air, and that particularly in the cold season of the northern climate, whatever the reason, the most glaring disagreements exist. This condition is well known, and it makes no difference whether the fresh air enters a room through an open window or is introduced by an artificial ventilating apparatus. We must further acknowledge that it is difficult, nay, useless, to combat the idea that the best and purest air is not secured from and through open windows when surroundings are park-like-in other words, ideal; but that it is easily combated when windows face illsmelling, dirty and dusty streets, courts or back yards.

It can therefore be easily proved that artificial ventilation is unnecessary in a spacious country home when inhabited by few persons, but on the other hand, it has been proved that humanity does wilt and waste away in overcrowded factories, schools, offices and laboratories unless artificial means for supplying fresh air and for removal of vitiated air, in addition to window ventilation, are provided.

* Read before the Section on Hospitals at the Sixty-Fifth Annual Session of the American Medical Association, Atlantic City, N. J., 
With proper application of engineering data and skill, fixed quantities of air can be moved through long distances and heights, even though large and powerful machines may be required in the most difficult cases. As records of long distances we must think of the artificial ventilating systems required for the building of railroad tunnels, where air for the tunnel builders was driven to their working places through pipes frequently from 6,000 to 8,000 feet long.

As a record of height, we may mention the Woolworth building in New York City, covering an underground area of 225 by 292 feet. The vitiated air of the cellar (largely containing the engine and boiler rooms) and of the basement, containing underground safe-deposit vaults, swimming pools, restaurants, kitchen, etc., is collected, and thence, with an ordinary blower, requiring but little power, discharged above the roofs. In one case the horizontal distance is as much as 360 feet and the vertical distance up to the fiftieth floor about 710 feet, making a total air travel of 1,070 feet.

For over ten summers an artificial cooling, humidifying and ventilating plant has been in operation in the New York Stock Exchange, where 1,500 persons are busily engaged with closed windows, as is necessary where cooling is desired. Of course, this room is not cooled to the constant winter temperature of 68. The room temperature best liked by the average person seems to bear a fixed relation to the outside temperature and the vapor contents. The most suitable inside temperatures with corresponding outside temperatures at about 60 per cent. humidity are as follows :

$\begin{array}{ll}68 \text { outside } & 68 \text { inside } \\ 75 \text { outside } & 72 \text { inside } \\ 80 \text { outside } & 74 \text { inside } \\ 85 \text { outside } & 76 \text { inside } \\ 90 \text { outside } & 78 \text { inside }\end{array}$

Many banking rooms having very large windows are located on the street level of lower New York City, but have, nevertheless, artificial ventilating plants. While windows in large banking rooms can be but seldom opened in the winter months because the quietly sitting bank people complain of unbearable drafts, it is even preferred in many cases to keep them closed in the summer months. The reason for this is that the dust from the streets, the cinders from smoke flues, and the latest nuisance of gases from the motors of automobiles and trucks will come into the rooms with the "fresh air" as secured by the windows. Noise from street traffic is also found most objectionable for rooms of this kind.

It would, finally, be extremely simple to cite many theaters, factories, laboratories, toilets, etc., to impress further the importance of artificial ventilation in our advanced civilization, with its ever increasing indoor life.

As to the air supplied by a well-designed ventilating apparatus, proper operating conditions taken for granted, it may be worse or better than that secured from the windows for reasons already stated. It is simple to temper the air with our common steam and hot water heating systems and their common heating surfaces without taking away any of its life-giving qualities. Air can be introduced or taken out near the top or near the bottom of a room. In the greatest part of the United States it is best to supply air at the top, because a larger amount can be introduced for the greater part of the time with the least draft; but in the summer months it is frequently found that the best results are secured in "reversing" the air currents, that is, introducing the air at the bottom and removing it at the top. The reversing of the air currents can be easily, cheaply and positively accomplished by the operation of a single damper.

Dusty air can be easily cleaned of its larger mechanical impurities without undue expense by means of air washers and air filters. When air washers are used there is, in case of non-operation, always the possibility and danger of water becoming stagnant. Dry filters of the cheese-cloth kind are, therefore, more "fool proof" from this point of view, but not so effective as far as dust removal is concerned. The use of air washers for filtering purposes will at the same time moisten the air, and will also cool the air at such times as the outside air is relatively dry. Under what conditions air moistening is important to health has as yet not been scientifically settled, but it mainly depends on whether the climate is ordinarily dry or moist. With dry filters, air-moistening pans may be used, and again there is the danger of stagnant water in case of non-operation, if the pans are not drained out properly.

Artificial cooling with dehumidifying, while probably important in warm and moist climates, is on account of the usually high operating expenses, very seldom done, but cooling effects by means of desk fans, due to rapidly moving air currents, may be secured at little. cost.

Finally, we may add ozone to the air at little expense for "bacteria removal," etc. While again the researches of the good of this treatment of air are not conclusive, it seems, nevertheless, to be the concensus of opinion of doctors who have given the matter consideration that as much harm may be done to the human beings as to the elusive microbe.

We are, therefore, quite positive in making the statement that we can "condition" the air supply of an artificial ventilating plant to almost any extent. On the other hand, the less "conditioning" necessary, with the exception of the heating and cooling of air and of adding moisture (which depend entirely on the climatic conditions), the better usually the ventilating apparatus is. Air for any artificial ventilating apparatus should preferably be taken from a point that is so pure and clean as to make any other "air conditioning" unnecessary, which, unfortunately, is but seldom possible in our crowded cities.

As to the heat required for warming the cold air coming into the windows or as supplied by the artificial ventilating apparatus, only two heat mediums need be considered at the present time, and they are steam and water.

Steam is usually at low pressure, and with the ordinary commercial heating surfaces the air can be warmed to about $140 \mathrm{~F}$. If water is the heat carrying medium it may be circulated by gravity actions or by pumps, and in either case it is with commercial heating surfaces difficult to heat the air to more than $130 \mathrm{~F}$. Steam (as well as water, if its circulation is forced by pumps) has been carried great distances from one central point, and a distance of a mile is not unusual any more.

After these few, necessarily short, general remarks on ventilation and ventilating systems for different kinds of buildings, the question now arises, Where does the hospital stand in relation to ventilation, and where does it materially differ from other buildings so far as 
ventilation is concerned? Consider first of all that any large hospital contains many different rooms, serving may different purposes. For the greater part of this country, active air supply and exhaust ventilation are usually required in operating rooms, operating theaters, bathing and therapeutic departments, dispensaries and underground boiler and engine rooms, kitchens, laundries, etc. Practice has also proved that the air supply must be warmed to different temperatures. A low temperature is necessary in cases in which a heat removal is desired, and a high temperature must naturally be carried for rooms having persons with scant or no clothing.

Exhaust ventilation for all rooms in which odors, gases and vapors are created is absolutely necessary. Among these rooms we may mention toilets, utility rooms, slop and specimen closets, laboratories, store rooms, animal rooms, etherizing and sterilizing rooms. It is of course realized that there may be conditions in any climate in which in each instance any room may be built of such large area and height as to make artificial ventilation unnecessary. If it were attempted it would probably be found that building and operating costs would be greater, provided as good conditions were to be secured in these rooms without artificial ventilation as with artificial ventilation.

Bedrooms for doctors and nurses should be so well located as not to require any artificial ventilation.

At present, however, when the necessity of artificial ventilation of a hospital is considered, the ward seems to be the one point on which the entire dişcussion centers; and frequently if the wards have no artificial ventilation, but many of the rooms mentioned above have, it is simply stated that the hospital has "no artificial ventilation."

As to the wards, it must be said that they usually occupy the choicest location of the site. Furthermore, most hospital sites are naturally well chosen as far as sun exposure and prevailing winds are concerned, and regulations as to unnecessary and objectionable noises are enforced in all large cities. In addition, the rooms are large, figures showing that the cubic contents per bed in a ward are usually four times that provided per person in good offices and eight times that in a schoolroom. Again, most wards have windows on two or three sides, making through draft possible. Admitting that conditions are in every way ideal, what, then, are the possibilities of securing in all kinds of climatic wind and weather conditions the much-wanted air renewal by the windows?

The opening of windows is ordinarily not objected to by anybody when the inside and outside temperatures are substantially the same, or when the outside temperature is higher. If it is some degrees cooler outside than inside and the cold air enters through windows, it mixes but exceedingly slowly with the warm room air, and consequently it sinks to the floor, thus creating a difference of temperature between floor and height of head, and chilling of the occupant may take place. In addition, excessive drafts are also occasionally created under careless openings of windows on gusty, windy days. Of course the doctor, busily engaged or walking through the room, or a patient in bed covered well with blankets, will but seldom find drafts and unequal temperatures objectionable. Still, drafts exist, as we all know, and any heating engineer can quote many experiences where even the downdrafts due to heat transmission from tightly closed large windows in business and amusement places, or in churches and halls, are found annoying by most persons. If the same persons do not object to in-drafts from open windows in a hospital, it is because of the usual uncomplaining ways which practically all persons pursue in dealing with any arrangement the "doctor" makes, the great and good man in the time of need and distress. His word is law, and it is but right that it should be-in the ward and sickroom.

It is not in the province of the ventilating engineer to decide whether or not, and how far, unequal temperatures and cold drafts may be harmful to the human body, all the more to the ailing human body. From my own observations in other rooms the habit and disposition of each individual should be taken into account. Consider also that there are wards for bodily and mentally sick patients, for quiet and restless feverish patients, for patients with external and internal sicknesses, for patients that require and do not require bed treatment, for patients with contagious diseases, etc. The matter is still more complicated when we consider that there are wards with all these different kinds of patients for adults, children and babies.

As a final consideration, may it not be proper to point out that hospitals, and with them wards, are necessary on the Panama Canal as well as in Alaska? It is questionable that there is a ventilating engineer who would advocate the closing of windows in a ward in the former place, with perhaps 110 in the shade, and rely for the best air conditions on the artificial ventilation without cooling, or that there is a doctor who would maintain that it is best for securing ventilation to open windows in $-50 \mathrm{~F}$. and let-50 air directly enter a window instead of warming it first over steam coils. It is evident that climate conditions form an important part in deciding whether or not artificial means of supplying air in a ward are necessary and valuable.

Generally speaking, it is, of course, but right for the ventilating engineer to presume that if certain methods of ventilation in a certain climate are appreciated by healthy persons, such methods ought to be also appreciated by sick persons! Indeed, who will question the correctness of the Samaritan view that if at all possible sick persons should be still better taken care of ?

If, therefore, the men in charge of the best bank, business and commercial houses, department stores, insurance offices, theaters, lecture rooms, etc., find it so often profitable to provide artificial ventilation for the same, why should it not be good for a ward? These and similar questions the designing engineer seeks in vain to answer to himself when he sees his ventilating plants in other buildings usually operating successfully, even though for obvious reasons not pleasing to every one, but finds his work in one department of the hospital lying idle for no specific or scientific reasons. If as a reason an undue high operating expense is given, or questions are dismissed with such familiar answers as "no artificial" ventilation is necessary in "our climate" for "our wards" with "their large windows," "fine exposure," "special bed arrangement," with our "carefully instructed nurses manipulating the windows and window ventilators," no particular harm is done. If, however, the non-operation is put on the score that all artificial ventilation is wrong, much harm is done to those who perforce have to be in places less fortunately located than most wards in hospitals.

That the operating expenses should present no insurmountable obstacles, the accompanying table may prove. 
In looking over the schedule it will be noted that the installation expenses are considerably higher for an artificial ventilating apparatus than those of merely making provision for heating by radiators an equal amount of air entering the windows. It will increase the building expenses all the way from $\$ 12.20$ to $\$ 19.80$ per bed, according to the apparatus selected. While this would seem considerable, still, it cannot be called excessive when one considers that the entire cost of building construction and equipment of a hospital is frequently from $\$ 4,000$ to $\$ 5,000$ per bed; in other words, the building expenses are increased approximately 0.5 per cent. No allowance, however, has been made for the possible increased cost of providing the required space conditions of blowers and flues. There are cases in which the additional cost is neglible, whereas in other cases the additional cost is considerable.

AVERAGE THEORETICAL COSTS OF INSTALIING AND OPERATING WINDOW AND ARTIFICIAL VENTILATION *

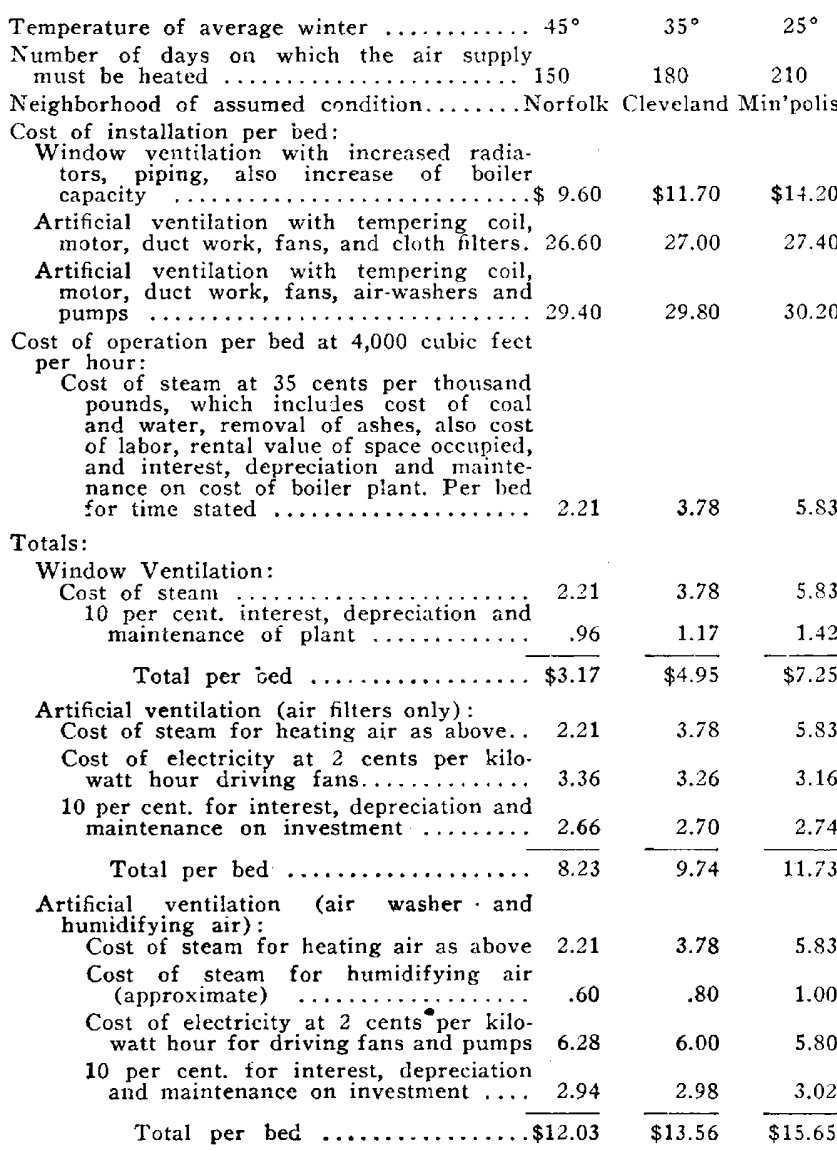

The results are average conditions for hospitals of say 500 patients in which coal and labor is of average cost. Operating expenses will operating expenses for loeating of any kind are included in these figures. conditions; twenty-four-hour service for running blowers, exhaust fans, pumps, etc., and 365 days per year.

It should also be noted that the cost for electric current appears rather high, but the artificial ventilation has beer. figured to run all the time (twenty-four hours per day and 365 days per year), and air is to be supplied under pressure by a blower and exhausted by an exhauster.

Similarly the cost in operating expenses under the same climatic conditions are approximately increased from $\$ 4$ to $\$ 8$ per bed per year, according to the apparatus installed. Hospitals seem to expend not less than $\$ 800$ per bed per year for the maintenance and operation, interest charges, etc. Consequently on this basis the operating expenses would be increased by the artificial ventilation from 0.5 to 1 per cent. If we were to reduce the operating expenses for artificial ventilation to a daily basis we would find that they would amount to the small sum of from 1 to 2 cents per day per bed over the window ventilation.

These figures are based on heating the air by a steam-heating apparatus, and the difference in expense for hot water heating will be slightly less.

In conclusion, may I be permitted to express the hope that the efforts of this symposium may at least result in qbviating the of tentimes reckless criticism of all artificial ventilation by the medical profession when discussing ward ventilation? If not, the prediction would seem in order that there will be retrogression instead of progress if the ultimate solution of proper ventilation of some of our subways and tunnels, of some of our factories with poisonous dust and gases floating in the air and inhaled by the workmen, of dingy offices, of ill-smelling moving picture show places, of some of our stuffy hot engine and boiler rooms, our schools and lecture rooms, our hot kitchens and laundries, etc. Living and healthful conditions depend in thousands of these places on artificial ventilation, and if it were altogether discarded, more institutions for taking care of sick and maimed must be built in the future than ever before. On the other hand, it is also realized that it is best not to have air conditions depend solely on artificial means, and that all the so-called "air conditioning" never has to most people, if indeed to any at all, the same effect as at times an open window, which is particularly true in the warmer weather. In our city and manufacturing life, however, ideal air conditions do not now, and probably never will exist, and therefore artificial ventilation will always be called on to do its share in overcoming the shortcomings of window ventilation in many of the hundreds of different confined spaces required by our complex civilization.

\section{A COMPARISON OF THE HOSPITAL OF OLD WITH THE MODERN STRUC'TURE* \\ T. J. VAN DER BENT NEW YORK}

Unreliable history only can tell us about the hospital of long ago. We are not well informed as to how the first hospitals were built, and thus it is difficult to make a fair comparison between the old and the new. Very little data can be depended on. A few plans have come to 11s, which, together with some stories of perhaps the worst type of old hospitals, have given us a little light. Altogether, our information is very insufficient, very scant, and unreliable. We may consider it as certain that the church - the Christian church - is responsible for the earliest hospitals. Whatever did exist in Greece and Rome in the shape of shelters and lodging houses, which at times were also used for the care of the sick, were only the forerunners of the real hospital.

* Read before the Section on Hospitals at the Sixty. Fifth Annual Session of the American Medical Association, Atlantic City, N. J.,
Tune. 1914. 